\title{
Greening the building envelope, façade greening and living wall systems
}

\author{
Katia Perini ${ }^{1}$, Marc Ottelé ${ }^{2}$, E. M. Haas ${ }^{2}$, Rossana Raiteri ${ }^{1}$ \\ ${ }^{1}$ Faculty of Architecture, University of Genoa Stradone S. Agostino, 37 - 16123 Genoa, Italy; katiaperini@hotmail.com \\ ${ }^{2}$ Faculty of Civil Engineering and Geosciences, Delft University of Technology Stevinweg 1, 2628 CN Delft, P.O. Box 5048, The \\ Netherlands; M.Ottele@tudelft.nl
}

Received 5 May, 2011; revised 12 May, 2011; accepted 21 May, 2011.

\begin{abstract}
For greening the building envelope several concepts can be used, for example green roofs, façades greened with climbing plants or living wall systems (modular pre-vegetated panels), etc. Greening the building envelope allows to obtain a relevant improvement of the its efficiency, ecological and environmental benefits as well as an increase of the biodiversity. Since the interest restoring the environmental integrity of urban areas continues to increase, new developments in construction practices with beneficial environmental characteristics take place, as vertical greening systems. Applying green façades is not a new concept and can offer multiple benefits as a component of current urban design; considering the relation between the environmental benefits, energy saving for the building and the vertical greening systems (material used, maintenance, nutrients and water needed) the integration of vegetation could be a sustainable approach for the envelope of new and existing buildings.
\end{abstract}

Keywords: Façade Greening; Living Wall Systems; Nature In Cities; Environmental Benefits;

Environmental Impact; Sustainability

\section{INTRODUCTION}

The ecological theories, from 1866 up until today, have contributed to the diffusion of a better awareness as far as our actions on a global level are concerned. The attention towards themes regarding ecology and sustainability in the last fifty years has developed with different intensities in parallel to a series of political and historical events, such as the first big energy crisis or the establishment that the hole in the ozone layer exists in 1985 [1]. The concept of sustainability has become a key idea in national and international discussions following the publication of the Brundtland Report (1987) and the 1992 Rio 'Earth Summit'. It was given further prominence in the context of the 2002 World Summit on Sustainable Development held in Johannesburg [2] and with the most recent Copenhagen Conference of 2009.

Considering the concept of sustainability the building environment is responsible of almost $40 \%$ of the global emissions. What can be defined as sustainable or ecoarchitecture represents an attempt to respond to global environmental problems and to reduce environmental impacts due to the building and housing industry, which include the exhaustion of natural resources, the emission $\mathrm{CO}_{2}$ and other greenhouse gases [3].

The integration of vegetation on buildings, through green roofs or vertical greening, allows obtaining a relevant improvement of the building's efficiency, ecological and environmental benefits, and it can be an opportunity to realize more "urban forestry". The benefits gained thanks to the use of vegetation are the subject of studies and researches starting from the seventies [4]. During this period the first projects which revolved around nature and the environment emerged such as the works of the SITE group, Emilio Ambasz, Rudolf Doernach, and Oswald Mathias Ungers.

Green façades offer the potential to learn from traditional architecture, the earliest form of vertical gardens dates from 2000 years ago in Mediterranean region, but also to incorporate advanced materials and other technology to promote sustainable building functions [5]. It is a good example of combining nature and buildings (linking different functionalities) in order to address environmental issues in dense urban surroundings [6], since urban centres today are currently searching for areas to plant vegetation, due to the lack of space, in order to transform the carbon dioxide produced by traffic and heating into carbon hydrates and oxygen.

The application of vegetation as a vertical skin can drastically change its aesthetics and have a positively 
influence on comfort and well being in and around the building in question [4]. The ecological and environmental benefits regard, as for green roofs, the improvement of air quality and reduction of air pollution, mainly related to reduction of fine dust levels [7], increase of biodiversity, the reduction of the heat island effect in urban areas due to the lower amount of heat re-radiated by greened façades and the humidity affected by the evapostranspiration caused by plants and indirect benefits as energy savings for the building. In fact both the growing medium and the plants themselves provide insulation and shade which can reduce, especially in Mediterranean area, energy for cooling and improve the indoor and outdoor comfort [8]. Beside these benefits also social and economical values are involved, with respect to the real estate market, the improve of durability and better psychological feelings of citizens.

\section{VERTICAL GREENING SYSTEMS, DEFINITIONS AND CHARACTERISTICS}

Vegetation can be seen as an additive (construction) material to increase the (multi)functionality of façades or buildings. Vertical green, also commonly referred to as a "vertical garden", is a descriptive term that is used to refer to all forms of vegetated wall surfaces [9]. Vertical green is the result of greening vertical surfaces with plants, either rooted into the ground, in the wall material itself or in modular panels attached to the façade and can be classified into façade greening and living walls systems according to their growing method [10,5].

Green façades are based on the use of climbers attached themselves directly to the building surface (a), as in traditional architecture, or supported by cables or trellis (b, Figure 1). In the first case climbers planted on the base of the building allows to obtain a cheap façade greening but with possible implications for any building works that need to be carried out (for example like damages, maintenance of the façade, see Figure 3), besides that some climbing plants can grow 5 or $6 \mathrm{~m}$ high, others around $10 \mathrm{~m}$ and some species at least $25 \mathrm{~m}$ [10].

The plant choice affects the aesthetical and functional aspects of a greened façade. An evergreen plant protects the façade from wind flow, snow and rain in winter seasons, which can be relevant especially in the temperate climate or for northern exposed façades. A deciduous climber allows the building envelope to change visually and affects also its performances; this type of vegetation is more suitable for the Mediterranean climate, since in many cases it is not necessary, even during winter seasons, to have a protection against environmental parameters and the sun radiation can warm up the building envelope. Beside this, in the case of an indirect greening system, where vegetation is supported by cables or meshes, many materials can be used as support for climbing plants as, for example, steel (coated steel, stainless steel, galvanized steel), types of wood, plastic or aluminium. Each of the materials enumerated changes the aesthetical and functional properties due to the different weight, profile thickness, durability and cost.

The indirect greening systems can be combined with planter boxes at different heights of the façade (c, Figure 1). In this case the system requires, if the rooting space is not sufficient, nutrients and a watering system. If nu- trients and a watering system are needed, it can be de- fined as a living wall system (LWS).

Living wall systems, which are also known as green walls and vertical gardens, are constructed from modular panels, each of which contains its own soil or other artificial growing mediums, as for example foam, felt, perlite and mineral wool, based on hydroponic culture, using balanced nutrient solutions to provide all or part of the plant's food and water requirements [10]. The plant type for these systems is normally evergreen (as small shrubs) and not naturally growing in vertical. Many systems have been developed in the last few years, each one of which with different characteristics, starting from the growing medium. For example the living wall systems shown in Figure 2 have different principles of growing and conceptions: the LWS based on plastic planter boxes

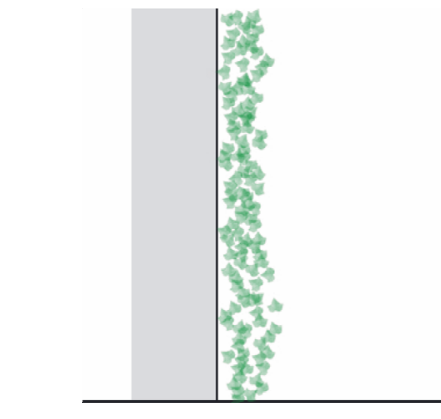

(a)

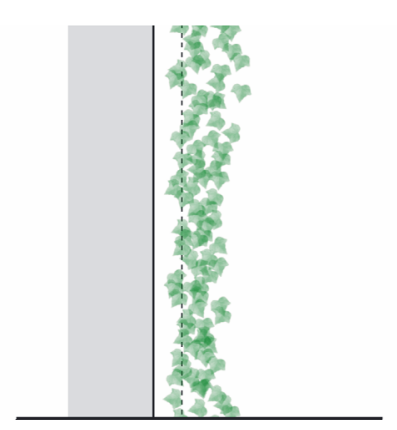

(b)

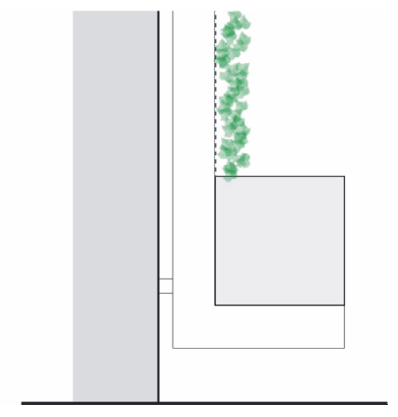

(c)

Figure 1. Direct greening system (a), indirect greening sys- tem (b), indirect greening system combined with planter boxes (c). 


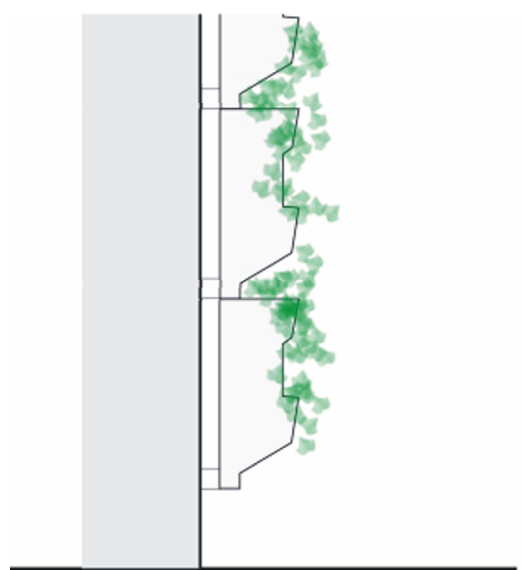

(d)

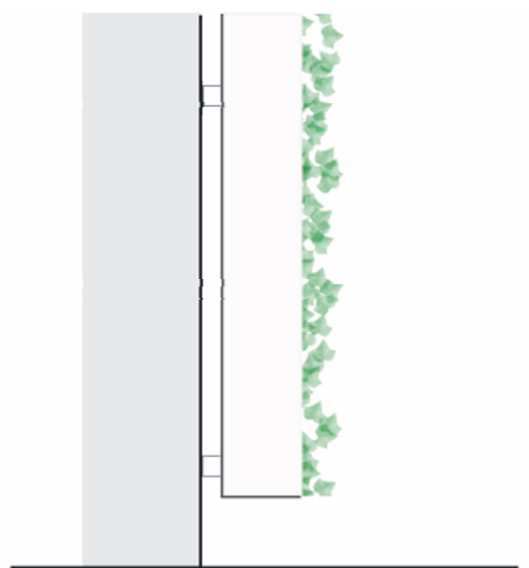

(e)

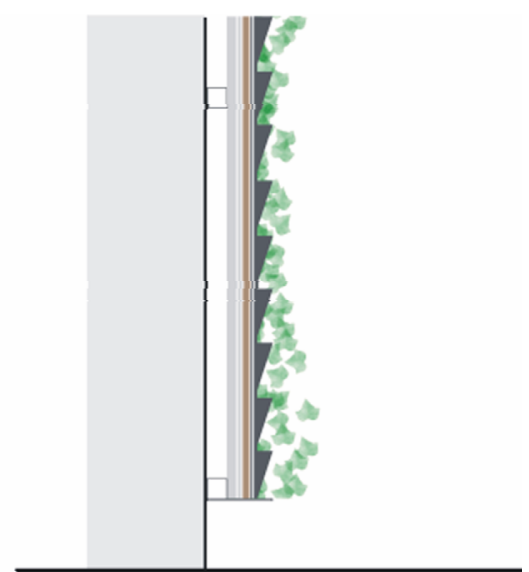

(f)

Figure 2. LWS based on planter boxes (d), LWS based on foam substrate (e), LWS based on felt layers (f).
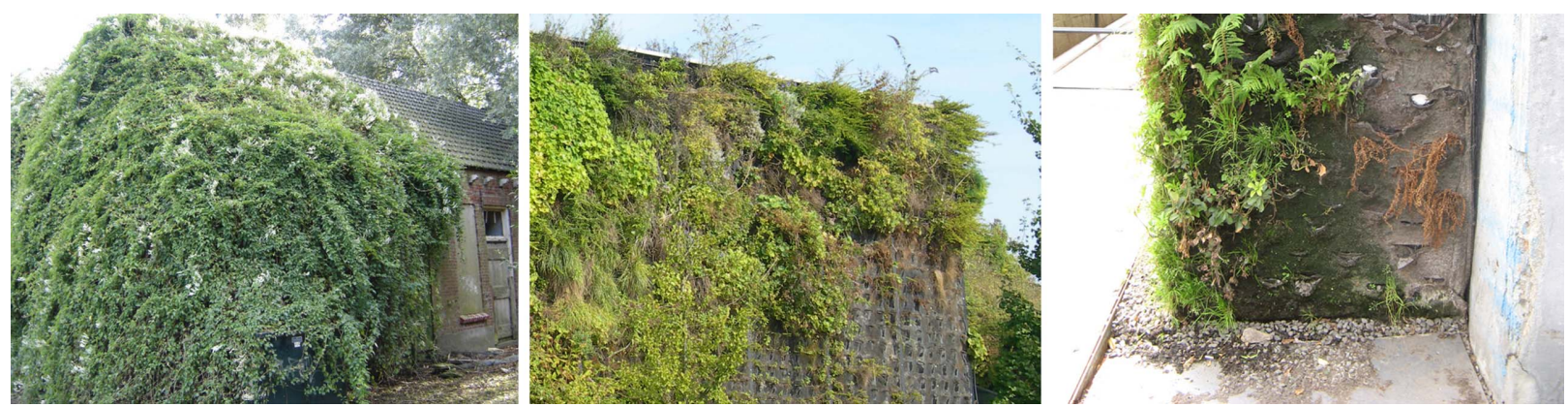

Figure 3. Examples of possible damages due to the lack of maintenance and to design mistakes.

(HDPE) is filled with potting soil (d), the LWS based on a foam substrate with steel baskets as support (e) and the last system shown (f) is a living wall system based on several felt layers, working as substrate and water proofing, supported by a PVC sheet.

The living wall systems increase the variety of plants that can be used beyond the use of climbing plants and offers much more creative (aesthetical) potential. It is also possible to assume that, from a functional point of view, most of the living walls systems (LWS), compared to green, demand a more complex design, which must consider a major number of variables (several layers are involved, supporting materials, control of water and nutrients, etc.), on top of which they are often very expensive, energy-vorous and difficult to maintain. However the technology is new, up to now there are less experiences and more detailed investigations in various climate are needed to optimize the vertical greening systems (LWS).

Considering the large amount of systems available on the market in all Europe, it is possible to give an idea of the costs needed for installing the systems described.

Range of costs for vertical greening systems per $\mathrm{m}^{2}$ (in Euros): a) Direct greening system (grown climbing plants): $30-45 € / \mathrm{m}^{2}$

b) Indirect greening system (grown climbing plants + supporting material): $40-75 € / \mathrm{m}^{2}$

c) Indirect greening system with planter boxes (LWS):

- zinc-coated steel (galvanized steel) 600-800 €/m²

- coated steel $400-500 € / \mathrm{m}^{2}$

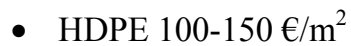

d) Living wall system based on planter boxes HDPE:

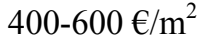

e) Living wall system based on foam substrate: $750-1200 € / \mathrm{m}^{2}$

f) Living wall system based on felt layers: $350-750$ $€ / \mathrm{m}^{2}$

Inside the range given, the costs depend on the façade surface (equipment) and height, location, connections, etc. It is clear that the living wall systems are much more expensive than the direct and indirect greening systems, this is due to the maintenance needed (nutrients and watering system), the materials involved, the design complexity. It also has to be ta ken into account the durability of the systems, for example a panel of a LWS based on felt layers has an average life expectancy ten years, but the LWS based on planter boxes is more durable 
(more than fifty years) [11]. Beside this a thorough design (de- tails of window ledges, doors, etc.) is necessary to avoid damages, as corrosion or rot, caused by water and nutria- ents leakage.

The green layer causes a shading effect, which also reduces the amount of UV light that will fall on building materials. Since UV light deteriorates the material and mechanical properties of coatings, paints, plastics, etc., plants will also have an effect on durability aspects. This is a beneficial side effect which has an influence on maintenance costs of buildings.

Greening the building envelope with living wall systems is a suitable construction practice for new building and retrofitting. In both situations, it is possible to have a higher integration within the building envelope by combining functionalities. For example in the case of the conventional bare wall constructed by several layers, it is possible to skip the outer façade element, since the protection against the environmental parameters can be absolved by a living wall system. For retrofitting projects an external insulation material outside can be easily covered with LWS panels.

\section{GREEN FAÇADES IN THE URBAN AREA}

It is possible to classify the various advantages into main areas, such as aesthetic, environmental and economics, even if those are related to each others. Greenery improves the visual, aesthetic and social aspects of the urban area, which have a high influence on the economical value of a building or neighbourhood, and contributes to enhancing human health. Urban green is widely recognized as therapeutic with a number of research studies illustrating this, for example, hospital patients who can see greenery out of the window recover more quickly than those who can not $[10,12]$.

The environmental benefits of greening the building envelope operate at a range of scale. Some of those only work if a large surface in the same area is greened and their benefits are only apparent at the neighbourhood or city scale. Others operate directly on the building scale.

The benefits related to the larger scale regard mainly the improvement of air quality and urban wildlife (biodiversity) and the mitigation of urban heat island effect [5]. The air quality improvement due to vegetation is mainly related to the absorption of fine dust particles and the uptake of gaseous pollutants such as $\mathrm{CO}_{2}, \mathrm{NO}_{2}$ and $\mathrm{SO}_{2}$. Carbon dioxide is used by plants for the photosynthesis process creating oxygen and biomass; nitrogen and sulphur dioxides are converted into nitrates and sulphates in the plant tissue. The fine dust particles (PM), especially the smaller size fractions $(<10 \mu \mathrm{m})$, are mainly adhered to the outside of the vegetation parts $[7,13]$; therefore vegetation is a perfect sink for airborne particles (Figure 6). Dust particles smaller than $2.5 \mu \mathrm{m}$ are relevant mainly in the dense urban area because they can be deeply inhaled into the respiratory system and cause damages for the human health [14].
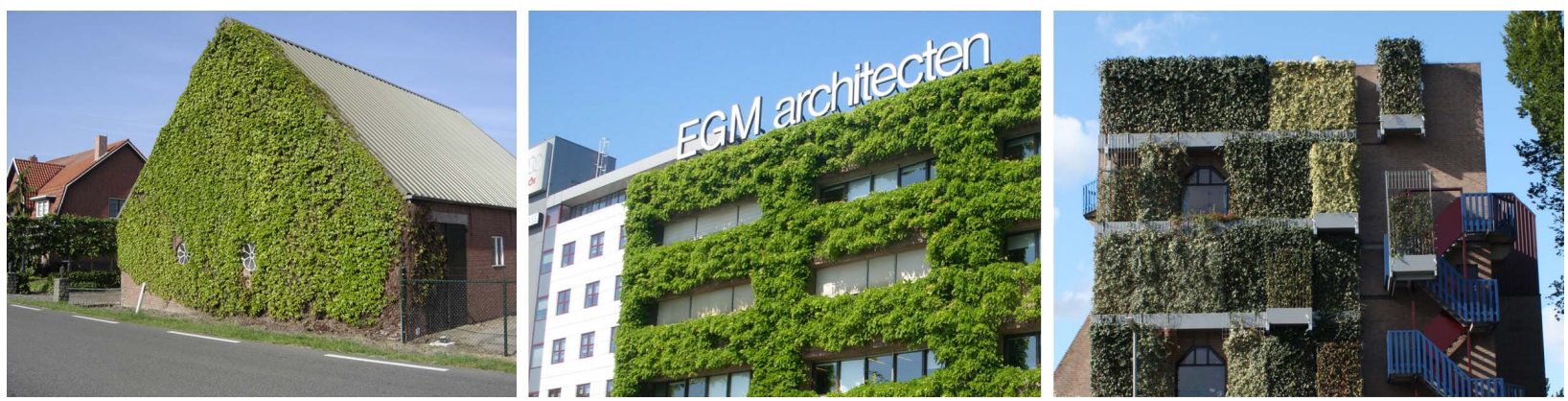

Figure 4. Direct greening system (a), indirect greening system (b), indirect greening system combined with planter boxes (c).
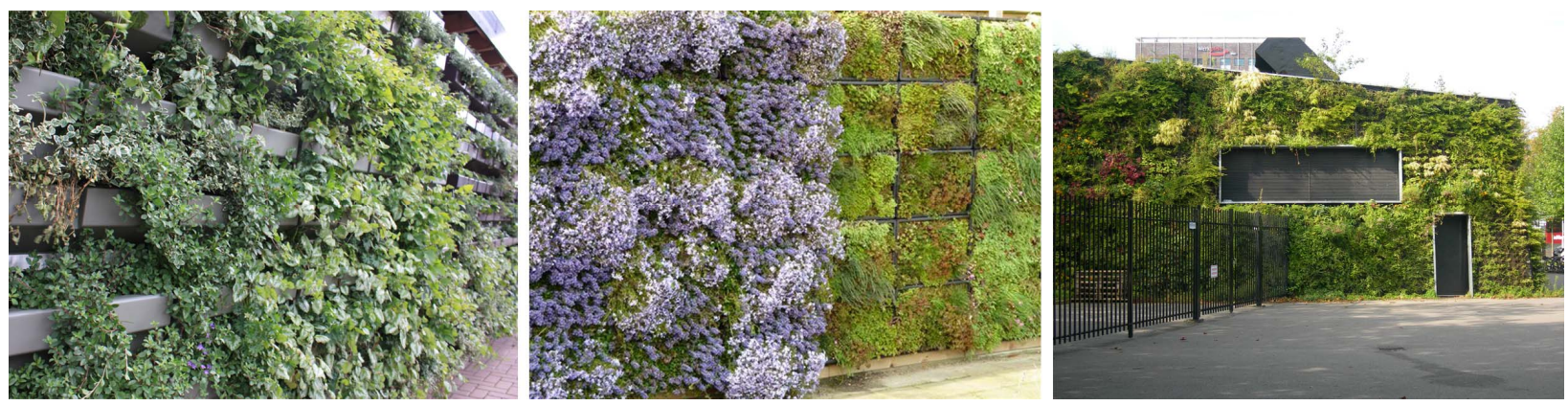

Figure 5. LWS based on planter boxes (d), LWS based on foam substrate (e), LWS based on felt layers (f). 


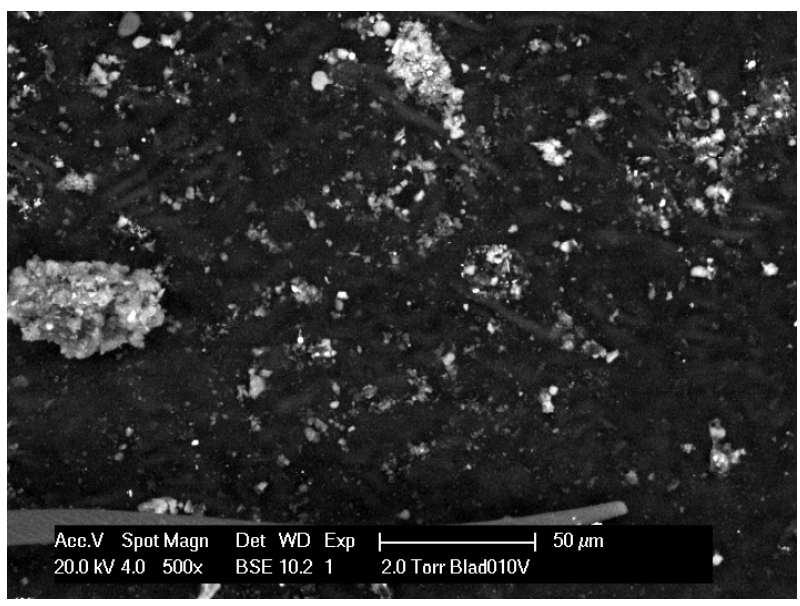

Figure 6. Electron microphotograph of particulate matter on the upper side of a leaf (Hedera Helix).

The urban heat island (UHI) phenomenon can cause air temperature in the cities to be $2-5^{\circ} \mathrm{C}$ higher than those in the surrounding rural areas, mainly caused by the amount of artificial surfaces (high albedo) compared with natural land cover $[15,16]$. Greening paved surfaces with vegetation to intercept the radiation can reduce the warming up of hard surfaces. By constructing green façades and green roofs great quantities of solar radiation will be adsorbed for the growth of plants and their biological functions. Significant amounts of radiation are used for photosynthesis, transpiration, evaporation and respiration [17]. $5-30 \%$ of the remaining solar radiation is passing trough the leaves and is affecting the internal climate of buildings when it passes the façade or roof. In the urban area, the impact of evapotranspiration and shading of plants can significantly reduce the amount of heat that would be re-radiated by façades and other hard surfaces. A literature study conducted by Onishi et al [16] shows a temperature reduction of $2-4^{\circ} \mathrm{C}$ due to the covering of areas with trees.

The effect of evapotranspiration and shading on the humidity level and temperature influences also the building microclimate, indoor and outdoor. As a conesquence, especially in warmer climates, the cooling potential can lead to significant energy savings for air conditioning [18]. The cooling potential of green façades or vertical green is discussed in many studies. Field measurements, conducted in Germany, on a plant covered wall and a bare wall by Bartfelder and Köhler [19] shows a temperature reduction at the green façade in a range of $2-6{ }^{\circ} \mathrm{C}$ compared with the bare wall. Another recent study by Wong et al [8] on a free standing wall in Hortpark (Singapore) with vertical greening types shows a maximum reduction of $11.6{ }^{\circ} \mathrm{C}$. This proves that a greened façade adsorbed less heat then a non greened façade and reveal itself in less heat radiation in the eve- ning and night. As shown in the photo below (Figure 7), taken with an infrared camera in The Netherlands during summer period (August), the surfaces uncovered (red) are warmer than the area covered by vegetation (green/ blue).

Green façades and living wall systems (LWS) have different characteristics that can have influence on the cooling potential above described; beside this it affects also the insulating properties. This comes, among other things, due to the thickness of the foliage (creating a stagnant air layer and shading the façade), water content, material properties and possible air cavities between the different layers.

The thermal transmittance (and thus insulation properties as well) of a building is among other things dependant and affected by the wind velocity that passes the surface of the building, a green layer can enhance the thermal properties of a façade. A study conducted by Perini et al [20] shows the potential of vertical green layers on reducing the wind velocity around building façades. Thanks to an extra stagnant air layer, which can be created inside the foliage, when the wind speed outside is the same as inside, $R_{\text {exterior }}$ can be equalized to $\mathrm{R}_{\text {interior. }}$ In this way the benefit on the thermal resistance of the construction can be quantified by an increase of $0.09 \mathrm{~m}^{2} \cdot \mathrm{K} \cdot \mathrm{W}^{-1}$. These results refer to the wind speed measured on a façade covered by a well grown direct greening system (a, Figure 1).

In the case of living wall systems the insulation properties of the material used can be taken into account, as well as the air cavity between the system and the façade and, in the case of a well grown vegetation, $R_{\text {exterior }}$ can be equalized to $\mathrm{R}_{\text {interior}}$, as for the direct greening system; for example the total thermal resistance of a living wall system based on planter boxes (d, figure 2) can be estimated as $\mathrm{R}=0.52 \mathrm{~m}^{2} \cdot \mathrm{K} \cdot \mathrm{W}^{-1}$. For both green façades

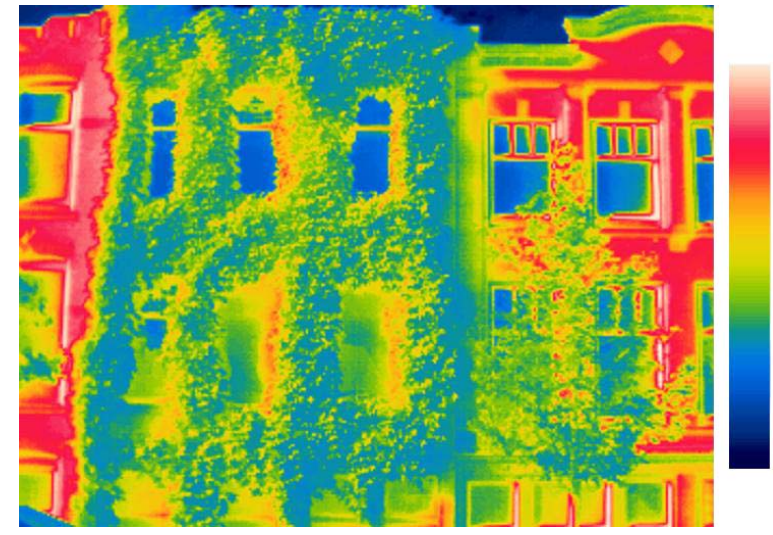

Figure 7. Photo of a façade covered by Boston ivy (Parthenocissus) rooted in the soil and applied directly against the façade taken with infrared camera (Delft, The Netherlands, summer 2009, 12 p.m., air temperature $21^{\circ} \mathrm{C}$ ) 
and living wall systems, this implies potential energy savings for building envelopes in warmer and colder climates.

\section{ENVIRONMENTAL IMPACT OF GREEN FAÇADES AND LIVING WALL SYSTEMS}

Beside the environmental benefits above described that greening systems allow to obtain, it is eventually not clear if these systems (all or some) are sustainable, due to the materials used, maintenance, nutrients and water needed. Sustainability can be defined as a general property of a material or a product that indicates whether and to what extent the prevailing requirements are met in specific application. These requirements, which relate to air, water and soil loading, have influences on well being and health of living creatures, the use of raw materials and energy, and also consequences for the landscape, the creation of waste and the occurrence of nuisance to surrounding environment [21].

A life cycle analysis can be an effective tool for evaluating the sustainability of a building element, with respect to the integral balance between the environmental load and the possible benefits. A study conducted by Ottelé et al. [22], regarding a life cycle analysis of four greening systems, shows the environmental burden profile in relation with the energy savings for air conditioning and heating achievable (according with Table 1), since only an estimation of the microscale benefits is taken into account in the research, for a Mediterranean climate situation and for a temperate climate one. The four greening systems analyzed in this LCA are: a direct greening system (a), an indirect greening system (b), a LWS based on planter boxes (d) and a LWS based on felt layers (f), the same shown in Figures 1 and 2.

As shown in Graph 1, the energy benefits provided by the greening options make a noteworthy impact in the LCA and are calculated for Mediterranean and temperate climate; for the Mediterranean climate the benefits calculated are roughly two times higher thanks to the energy savings related to the cooling potential. From this LCA research it can be concluded that:

- The direct greening system has a very small influence on the total environmental burden, for this reason this type of greening, without any additional material involved, is always a sustainable choice for the examined cases.

- The indirect greening system analyzed based on a stainless steel supporting system has an high influence on the total environmental burden.

- The LWS based on planter boxes has not a major footprint due to the materials involved, since the materials affect positively the thermal resistance of the system.
Table 1. Energy saving (calculated with Termo 8.0 software, [22]) for heating, energy saving for cooling and temperature decrease for Mediterranean and temperate climate based on Alexandri and Jones [18].

\begin{tabular}{|c|c|c|c|}
\hline Greening system & Benefit & $\begin{array}{c}\text { Mediterranean } \\
\text { climate }\end{array}$ & $\begin{array}{c}\text { Temperate } \\
\text { climate }\end{array}$ \\
\hline \multirow[t]{3}{*}{ Direct green } & $\begin{array}{l}\text { energy saving for } \\
\text { heating }\end{array}$ & $1.2 \%$ & $1.2 \%$ \\
\hline & $\begin{array}{l}\text { temperature de- } \\
\text { crease }\end{array}$ & $4.5^{\circ} \mathrm{C}$ & $2.6^{\circ} \mathrm{C}$ \\
\hline & $\begin{array}{l}\text { energy saving for } \\
\text { cooling }\end{array}$ & $43 \%$ & --- \\
\hline \multirow[t]{3}{*}{ Indirect green } & $\begin{array}{l}\text { energy saving for } \\
\text { heating }\end{array}$ & $1.2 \%$ & $1,2 \%$ \\
\hline & $\begin{array}{l}\text { temperature de- } \\
\text { crease }\end{array}$ & $4.5^{\circ} \mathrm{C}$ & $2.6^{\circ} \mathrm{C}$ \\
\hline & $\begin{array}{l}\text { energy saving for } \\
\text { cooling }\end{array}$ & $43 \%$ & --- \\
\hline \multirow[t]{3}{*}{ LWS planter boxes } & $\begin{array}{l}\text { energy saving for } \\
\text { heating }\end{array}$ & $6.3 \%$ & $6,3 \%$ \\
\hline & $\begin{array}{l}\text { temperature de- } \\
\text { crease }\end{array}$ & $4.5^{\circ} \mathrm{C}$ & $2.6^{\circ} \mathrm{C}$ \\
\hline & $\begin{array}{l}\text { energy saving for } \\
\text { cooling }\end{array}$ & $43 \%$ & --- \\
\hline \multirow[t]{3}{*}{ LWS felt layers } & $\begin{array}{l}\text { energy saving for } \\
\text { heating }\end{array}$ & $4 \%$ & $4 \%$ \\
\hline & $\begin{array}{l}\text { temperature de- } \\
\text { crease }\end{array}$ & $4.5^{\circ} \mathrm{C}$ & $2.6^{\circ} \mathrm{C}$ \\
\hline & $\begin{array}{l}\text { energy saving for } \\
\text { cooling }\end{array}$ & $43 \%$ & --- \\
\hline
\end{tabular}

- The LWS based on felt layers has a high environmental burden due to the durability aspect and the materials used.

Since the development in this field is growing rapidly especially the last three to four years, many systems with different materials and characteristics are available. The different systems and materials can have an influence on the environmental burden either positively and negatively. For example for the indirect greening system also other materials can be used as support for climbing plants, such as different types of wood, plastic, aluminum and steel, instead of a stainless steel mesh, and can have an influence on the environmental burden of the system roughly 10 times lower than the stainless steel mesh [21]. Beside this for living wall systems a sustainable approach can involve a higher integration within the building envelope by combining functionalities, since the protection against the environmental parameter can be absolved by the layers involved.

Greening the building envelope, considering the materials involved, that have a high influence on the environmental profile, and taking into account all the benefits (also the ones not quantifiable yet) is a sustainable option for new constructions and retrofitting.

\section{SUMMARY}

Vertical greening systems and theirs environmental benefits are the subject of studies and researches starting 


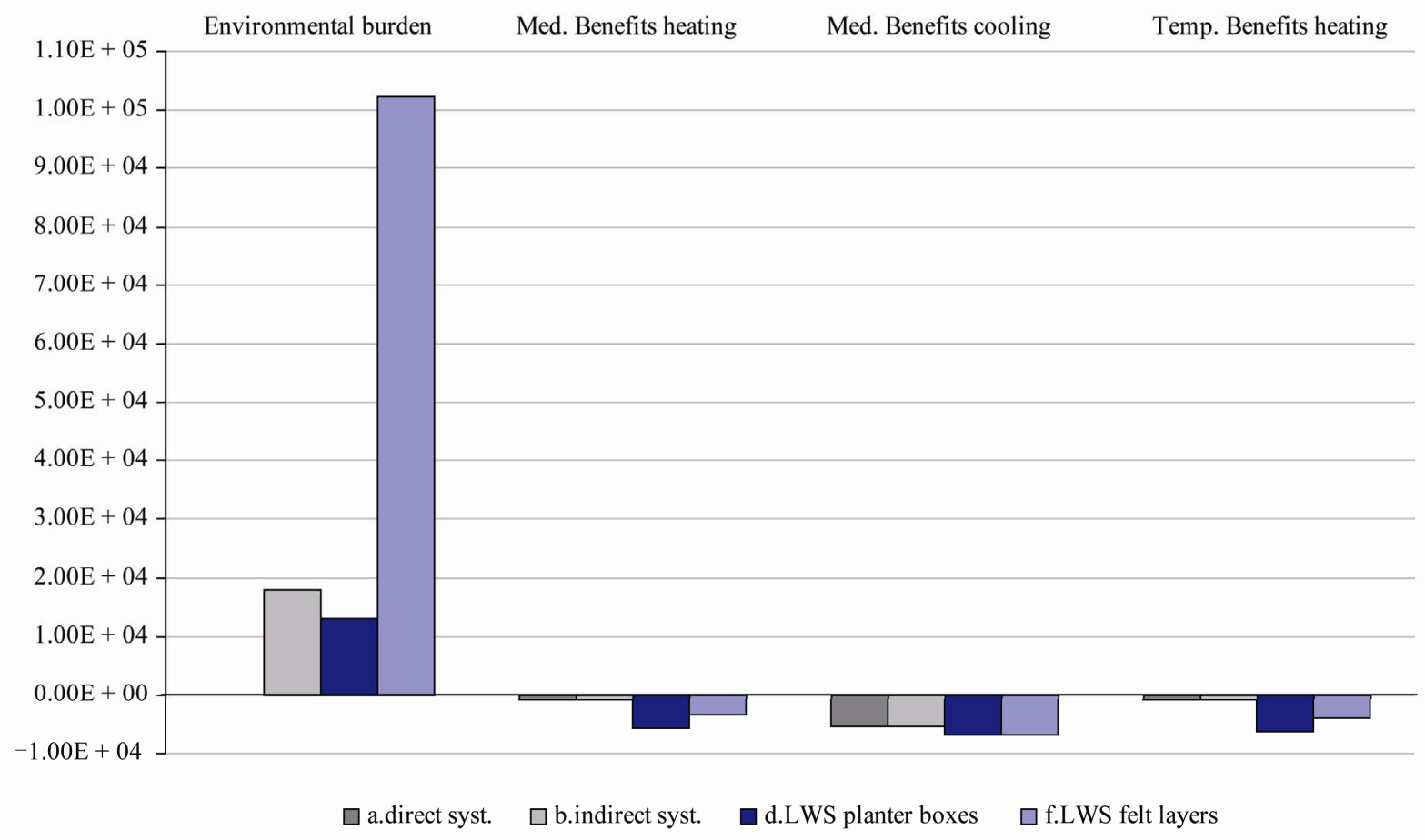

Graph 1. Total environmental burden (impact) for four greening systems (supporting systems + vegetation), benefits for heating and cooling for Mediterranean climate and benefits for heating for temperate climate according to Ottelé et al. [22].

from the seventies [4]; however it has not been approved as an energy saving method for the built environment. The most of the studies have been conducted about green façades (base on climbing plants), but still even those concepts are not fully investigated. Many researches can be deepened for quantifying the environmental benefits especially for the macroscale. Recent technical solutions are under development for vertical greening systems, as defined living wall systems (LWS). This is a new field to investigate, regarding the insulation properties, durability aspects, maintenance, plants choice related to the climate conditions, materials involved, etc. The systems design can take into account many aspects, such as the integration with the building envelope, a sustainable material choice considering the environmental impact but also the symbiosis between the growing medium and the vegetation, which is a key element for the success of the greening system. Also the economical aspects, related to costs savings due to possible reduction of energy needed for heating and cooling, have to be taken into account for avoiding a larger use of green envelops in the urban area. A process tree can be developed for urban design, new constructions and retrofitting projects, to afford the right choice of greening system, considering the main parameters, as the climate type and building characteristics, to avoid damages and maintenance problems caused by an inappropriate design. The multiple benefits of vertical greening systems could allow to a more sustainable urban design and to compensate the lack of green spaces inside dense cities for the wellbeing of the dwellers.

\section{ACKNOWLEDGEMENTS}

Department of Materials and Environment of Delft University, Faculty of Civil Engineering and Geosciences are acknowledged for the availability to allow a international cooperation with University of Genoa. The Department of Architectural Sciences of University of Genoa, Faculty of Architecture is acknowledged for the necessary financial support for the international cooperation.

Barbera Peters and Ben Vriesema are acknowledged for theirs photographs used in this article.

\section{REFERENCES}

[1] Cassinelli, G., Perini, K., "Estetica dell'architettura sostenibile.” Eurau '10, Naples, Italy pp. 67-72.

[2] Doughty M.R.C., Hammond G.P., 2004 Sustainability and the build environment at and beyond the city scale. Building and Environment Vol. 39, 2004, 1223-1233.

[3] Pulselli R.M., Simoncini E., Pulselli F.M., Bastianoni S., 2006. Emergy analysis of building manufacturing, maintenance and use: Em-building indice sto evaluate housing sustainability. Energy and Buildings 39 (2007) 620-628.

[4] Bellomo A., 2003, Pareti verdi, Sistemi editoriali, Napoli, Italy

[5] Köhler M., 2008, Green façades-a view back and some vision, Urban Ecosyst 11:423-436, doi 10.1007/s11252-008-0063-x 
[6] Bohemen, van, H., 2005. Ecological engineering, bridging between ecology and civil engineering, Aeneas technical publishers.

[7] Ottelé M. Van Bohemen H., Fraaij, A.L.A., 2010, Quantifyng the deposition of particulate matter on climber vegetation on living walls, Ecological Engineering 36 154162.

[8] Wong NH, et al., 2009, Thermal evaluation of vertical greenery systems for building walls, Building and Environment, doi:10.1016/j.buildenv.2009.08.005

[9] www.greenroofs.org

[10] Dunnet N., Kingsbury N., 2004, Planting Green Roofs and Living Walls, Timber Press, Oregon.

[11] Riedmiller, J., Schneider, P., 1992. Maintenance-free roof gardens: new urban habitats. Naturwissenschaften 1992; 79 (12):560-1.

[12] Ulrich, R.S., Simons, R., 1986, Recovery from stress during exposure to every day outdoor environments. In Wineman, J., Barns, R., Zimring, C., The costs of not knowing, procidings of the seventieth annual conference of the environmental research association, Washington DC.

[13] Stemberg, T., Viles, H., Carthersides, A., Edwards, M., 2010. Dust particulate absorption by Ivy (Hedera Helix L.) on historic walls in urban environments. Science of the Total Environment, 409 (2010) 162-168.

[14] Powe, N.A., Willis, K.G., 2004, Mortality and morbidity benefits of air pollution $\left(\mathrm{SO}_{2}\right.$ and $\left.\mathrm{PM}_{10}\right)$ adsorption attributable to woodland in Britain, Journal of Environmental Management , 70, 119-128 (2004).
[15] Taha, H., 1997. Urban climates and heat islands: albedo, evapotraspiration, and antropogenic heat. Energy and Buildings 25, 99-103.

[16] Onishi, A., Cao, X., Ito, T., Shi, F., Imura, H., 2010 Evaluating the potential for urban heat-island mitigation by greening parking lots. Urban Forestry \& Urban Greening 9 (2010) 323-332.

[17] Krusche, P., Krusche, M., Althaus, D., Gabriel, I., 1982. Ökologisches bauen. Herausgegeben vom umweltbundesamt, Bauverlag.

[18] Alexandri, E., Jones, P., 2008.Temperature decrease in a urban canyon due to green walls and green roofs in diverse climates. Building and Environment 43 (2008) 480493.

[19] Bartfelder, F., Köhler, M., 1987. Experimentelle untersuchungen zur function von fassadenbegrünungen, Dissertation TU Berlin 612S.

[20] Perini, K., Ottelé M., Fraaij, A.L.A., Haas, M., Raiteri, R., 2011. Vertical green systems and the effect on air flow and temperature on the building envelope. Building and Environment (2011), doi: 10.1016/j.buildenv.2011.05.009

[21] Hendriks, C. F., Bijen, J.MJ.M, Felix, F., Fraaij, A.L.A., Janse, H., de Munck, E.D., Reintjes, R.C., Schutte-Postma, E.T., Stroeven, P., Vogtlander, J.G., van der Wegen, G.J.L., 2000. Durable and sustainable construction materials. ISBN 90-75-365-30-6.

[22] Ottelé M., Perini, K., Fraaij, A.L.A., Haas, M., Raiteri, R., 2011. Comparative life cycle analysis for green façades and living wall systems. Journal of International Scientific Publications: Ecology \& Safety, Volume 5. 